\title{
Estudo de Viabilidade: Mercado Livre vs Mercado Cativo
}

\author{
FEASIBILITY STUDY: FREE MARKET VS CAPTIVE MARKET
}

Caio Teberge ${ }^{1}$ (D)ttps://orcid.org/0000-0003-4671-8985.

Eduardo Sodré1, ${ }^{2}$ (D)ttps://orcid.org/0000-0002-5793-8900.

1 Escola Politécnica de Pernambuco, Universidade de Pernambuco, Recife, Brasil,

2 Companhia Hidroelétrica do São Francisco, Recife, Brasil

E-mail do autor principal: Caio Teberge teberge@hotmail.com

\section{RESUMO}

O estudo de viabilidade permite que o consumidor de energia elétrica obtenha uma análise acerca da possibilidade de obter economia, de maneira que ele pode escolher se permanece no Mercado Regulado ou opta pela migração para o Mercado Livre. Para tanto, foi elaborado um estudo com base nos valores cobrados em cada ambiente de comercialização, analisando cada tarifa individualmente. Com base nisso, pôde-se observar que, no caso em questão,o Mercado Livre de Energia é uma boa alternativa quando comparado ao Mercado Cativo, uma vez que este é mais oneroso financeiramente quando comparado àquele. Além de evidenciar o modo de contratação mais econômico, o estudo proporcionou uma melhor compreensão sobre os mercados passíveis de negociação no âmbito energético, de forma que o usuário não precise ficar sempre vinculado aos preços e condições das concessionárias.

PALAVRAS-CHAVE: Mercado Livre; Mercado Cativo; Migração;

\section{ABSTRACT}

The feasibility study allows the consumer of electricity to obtain an analysis of the possibility of obtaining savings, so that he can choose whether to remain in the Captive Market or opt for the Free Market migration. For this purpose, a study was elaborated based on the amounts charged in each marketing environment, analyzing each tariff individually. Based on this, it could be observed that in the case in question the Free Energy Market is a good alternative when compared to the Captive Market, since the latter is more financially costly when compared to former. In addition to highlighting the more economical contracting mode, the study provided a better understanding of the tradable markets in the energy field, so that the user does not have to be always bound to the prices and conditions of the concessionaires.

KEY-WORDS: Free market; Captive Market; Migration; 


\section{INTRODUÇÃO}

Com o passar dos anos a competitividade do mercado fez a indústria olhar para um item importante dos seus custos: a energia elétrica, tido como um dos três produtos mais custosos na produção. Em fevereiro de 2018, o consumo industrial de eletricidade cresceu 3,9\% em relação a igual mês do ano anterior. Entre os maiores consumidores, destacou-se a indústria automobilística e a indústria extrativa de minerais metálicos, em especial, em Minas Gerais e no Pará, e o consumo da metalurgia de metais não ferrosos em São Paulo [1].

Até há pouco tempo, a única alternativa para essas indústrias era a contratação de energia por meio do Mercado Regulado, também chamado de Mercado Cativo. Neste ambiente os consumidores fazem contrato compulsoriamente com a distribuidora de energia local e ficam vinculados aos termos pré-estabelecidos pela concessionária, o que não é tão econômico.

É nesse panorama, que os consumidores têm procurado por melhores condições para a contratação de energia,que surge, como uma alternativa ao Mercado Cativo, o Mercado Livre de Energia Elétrica, ou Ambiente de Contratação Livre $\mathrm{ACL}$. Ele propõe ao usuário um menor preço e a flexibilização de alguns elementos do contrato, desde que o cliente opte por fazer a migração de um mercado para o outro.

Mais precisamente, o Mercado Livre de Energia foi criado em julho de 1995, com a Lei 9.074. Seu objetivo principal era diminuir o investimento em infraestrutura pelo poder público e incentivar o capital privado no setor. Além disso, sua criação deu origem a importantes reduções no custo com energia elétrica e um fortalecimento na competição entre as empresas do ramo energético brasileiras, buscando um setor mais eficiente e competitivo.

Com isso, o crescimento do $\mathrm{ACL}$ foi inevitável, visto queele proporcionou aos clientes, que antes eram obrigados a fechar negócio com as concessionárias de sua região, uma opção diferente para a contratação de energia elétrica.Os consumidores geralmente sãoatraídos pela possibilidade de os termos contratuais poderem ser negociáveis no Mercado Livre, inclusive o preço da energia consumida. De forma queas condições podem ser ajustadas da maneira que melhor convir às partes do acordo,sendo possível até a definição de um valor pré-fixado para o preço da energiaem todo o período de vigência do contrato.
Assim, será discutida a formação da tarifa no ambiente regulado e do preço no ambiente livre, identificando como se dará a mudança de cobrança da energia consumida ao optar pela migração. Ademais, uma análise acerca de qual seria a forma mais vantajosa de contratação de energia para o usuário.

\section{MERCADO LIVRE VERSUS MERCADO CATIVO}

O Mercado Livre de energia elétrica é o ambiente em que os consumidores podem optar livremente pelos seus fornecedores de energia. Em vista disso, consumidores e fornecedores negociam as condições de contratação de energia da melhor forma para ambos.

Já o Mercado Cativo é a opção padrão dos consumidores que adquirirem a energia no Ambiente de Contratação Regulada - ACR. Trata-se da contratação obrigatória por meio da distribuidora da região em que os clientes estão localizados. As tarifas do consumo de energia são definidas pela Agência Nacional de Energia Elétrica - ANEEL. Todos os consumidores residenciais estão nesse mercado, assim como algumas empresas comerciais, indústrias e consumidores rurais que não podem ou não optaram pela migração.

O poder da escolha da fonte de energia consumida e do parceiro comercial; a flexibilidade das condições de contratação, tais como preço, volume, prazo, garantias e reajustes e; o controle/previsibilidade dos gastos são os principais atrativos que motivam a migração para o Ambiente de Contratação Livre.

\subsection{Consumidores Aptos a Migrar}

Os consumidores que possuem, no mínimo, $3.000 \mathrm{~kW}$ de demanda contratada podem fazer a migração e contratar energia proveniente de quaisquer fontes de geração. Além da restrição ao nível de demanda contratada, as empresas que se conectaram ao sistema elétrico antes de 7 de julho de 1995 têm de receber a energia em tensão superior a $69 \mathrm{KV}$ para poder migrar, condição esta que não será mais exigida a partir de 2019 [2].

Consumidores que possuem demanda contratada igual ou maior que 500 e menor que $3.000 \mathrm{~kW}$, independentemente do nível de tensão, podem migrar, desde que contratem energia originária de usinas eólicas, solares, a biomassa, pequenas centrais hidrelétricas ( $\mathrm{PCHs}$ ) ou hidráulica de 
empreendimentos com potência inferior ou igual a $50.000 \mathrm{~kW}$, as chamadas fontes especiais de energia, esses são ditos Consumidores Especiais [3].

$\mathrm{Na}$ Figura 1 pode-se observar a migração dos consumidores livres no período entre março de 2017 e março de 2018.

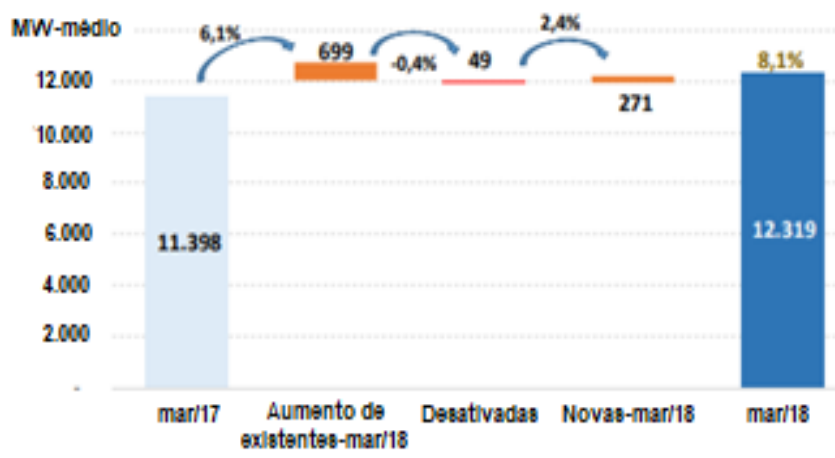

Figura 1: Migração dos consumidores livres: evolução do consumo em MW médios.

Fonte:InfoMercado Mensal no 129.

Na Figura 2 é possível visualizar a migração dos consumidores especiais nos meses entre março de 2017 e março de 2018.

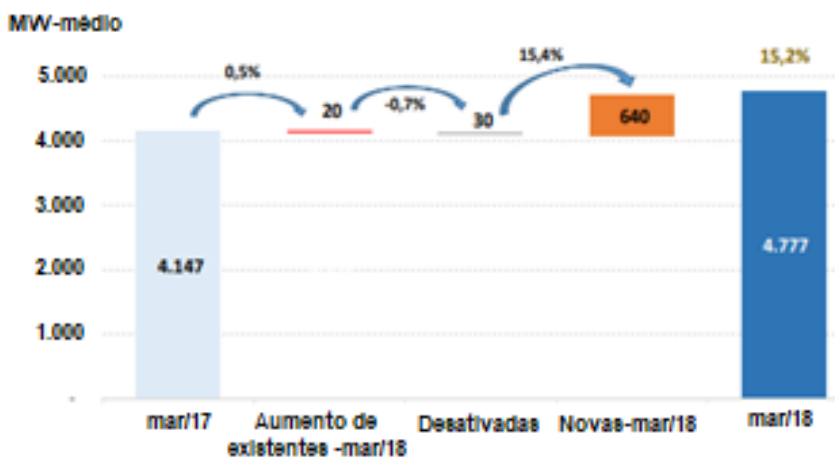

Figura 2: Migração dos consumidores especiais: evolução do consumo em MW médios.

Fonte: InfoMercado Mensal no 129.

Consumidores que possuem o mesmo CNPJ ou localizados em área contígua - sem separação por vias públicas - podem somar as cargas que consumem para atingir o nível de demanda de 500 $\mathrm{kW}$ exigido para se tornar consumidor especial. De modo que uma rede de supermercados, com dez unidades consumidoras (todas com o mesmo CNPJ), as quais possuem cada uma $50 \mathrm{~kW}$ de demanda contratada, poderá tornar-se um consumidor do grupo especial por comunhão de cargas, atingindo a demanda requisitada de $500 \mathrm{~kW}$.

\subsection{Tipos de Fontes}

A Lei 13.203 de 2015, com vigência a partir da contabilização de janeiro de 2017, estabeleceu novos limites para classificar os tipos de energia. Quanto à nomenclatura, a energia Especial confere lastro para consumidores "especiais" e a energia Incentivada confere desconto de $50 \%$ na utilização do fio para os geradores e consumidores que geram/consomem essa energia. A seguir, são apresentadas as principais fontes de energia e em qual tipo poderão comercializar a depender de sua potência injetada.

\subsection{Solar, Eólica e Biomassa}

As Usinas de Energia Solar podem comercializar energia em diferentes tipos de acordo com os parâmetros de período e potência. De modo que ela obedece a certa regra se a outorga foi concedida antes de 2016, caso contrário, as especificações se darão por uma regra distinta. Mais detalhes podem ser vistos na Tabela 1.

Tabela 1: Tipo de energia nas fontes solar, eólica e biomassa.

\begin{tabular}{|c|c|c|}
\hline \multicolumn{3}{|c|}{ Solar, Eólica e Biomassa } \\
\hline & Pré-2016 & Pós-2016 \\
\hline Até30 MW & $\begin{array}{c}\text { Incentivada } \\
\text { Especial }\end{array}$ & \multirow{2}{*}{$\begin{array}{c}\text { Incentivada } \\
\text { Especial }\end{array}$} \\
\hline 30 a $50 \mathrm{MW}$ & $\begin{array}{l}\text { Convencional } \\
\text { Especial }\end{array}$ & \\
\hline $50 \mathrm{MW}$ a $300 \mathrm{MW}$ & \multirow{2}{*}{$\begin{array}{c}\text { Convencional não } \\
\text { Especial }\end{array}$} & $\begin{array}{c}\text { Incentivada não } \\
\text { Especial }\end{array}$ \\
\hline $\begin{array}{c}\text { Acima de } 300 \\
\text { MW }\end{array}$ & & $\begin{array}{c}\text { Convencional não } \\
\text { Especial }\end{array}$ \\
\hline
\end{tabular}

Fonte: Os Autores.

\subsection{Hidráulica}

Já as Usinas Hidrelétricas têm uma composição diferente das demais citadas para a negociação de energia. Os detalhes podem ser observados na Tabela 2.

Tabela 2: Tipo de energia para fonte hidráulica.

\begin{tabular}{|c|c|c|}
\hline \multicolumn{3}{|c|}{ Hidráulica } \\
\hline Até30 MW & Pré-2016 & Pós-2016 \\
\hline 30 a $50 \mathrm{MW}$ & $\begin{array}{c}\text { Incentivada Especial } \\
\text { (Parcial) }\end{array}$ & $\begin{array}{c}\text { Incentivada } \\
\text { Especial }\end{array}$ \\
\hline $50 \mathrm{MW}$ a $300 \mathrm{MW}$ & $\begin{array}{c}\text { Incentivada } \\
\text { Especial (Parcial) }\end{array}$ \\
\cline { 1 - 1 } Acima de $300 \mathrm{MW}$ & $\begin{array}{c}\text { Convencional não } \\
\text { Especial }\end{array}$ & $\begin{array}{c}\text { Convencional não } \\
\text { Especial }\end{array}$ \\
\hline
\end{tabular}

Fonte: Os Autores. 


\subsection{Tarifação no Ambiente de Contratação Regulada}

A prestação dos serviços públicos de distribuição de energia elétrica é regulada conforme regras definidas nos contratos de concessão/permissão, celebrados entre as distribuidoras e a União, por intermédio da ANEEL. Nestes contratos, foram definidos três mecanismos de alteração tarifária: revisão tarifária periódica, reajuste tarifário anual e revisão tarifária extraordinária.

O processo de Revisão Tarifária Periódica tem como principal objetivo analisar, após um período previamente definido no contrato de concessão (geralmente de 4 anos) o equilíbrio econômicofinanceiro da concessão, reavaliando os custos eficientes e investimentos prudentes.

Os reajustes tarifários ocorrem anualmente, exceto nos anos em que ocorrem revisões tarifárias periódicas. O mecanismo de Reajuste Tarifário Anual tem como objetivo restabelecer o poder de compra da receita obtida por meio das tarifas praticadas pela concessionária, neutralizando o impacto da inflação.

Além dos reajustes anuais e das revisões periódicas, a ANEEL também pode realizar a Revisão Tarifária Extraordinária a qualquer tempo, quando algum evento provocar significativo desequilíbrio econômico-financeiro, ou em casos de criação, alteração ou extinção de tributos ou encargos legais, com impacto devidamente comprovado [3].

As regras de cálculo dos reajustes e revisão tarifária estão regulamentadas nos Módulos 2 e 3 dos Procedimentos de Regulação Tarifária PRORET, documentos de caráter normativo expedidos pela ANEEL que consolidam a regulamentação sobre os processos tarifários.

\subsubsection{DEFINIÇÕES}

As definições de ordem técnica foram obtidas em sua totalidade por meio de documento disponibilizado pela ANEEL em seu sítio (www.aneel.gov.br). No qual são adotados os seguintes termos e conceitos:

1.TUSD - Tarifa de Uso do Sistema de Distribuição: valor monetário unitário determinado pela ANEEL, em R\$/MWh ou em $\mathrm{R} \$ / \mathrm{kW}$, utilizado para efetuar o faturamento mensal de usuários do sistema de distribuição de energia elétrica pelo uso do sistema;

2.TUST - Tarifa de Uso dos Sistemas de Transmissão: TUSTRB, relativa ao uso de instalações da Rede Básica, e TUSTFR, relativa ao uso de transformadores de potência da Rede Básica com tensão inferior a $230 \mathrm{kV}$ e Demais Instalações de Transmissão - DIT, quando de uso em caráter compartilhado, conforme Resolução Normativa no 67/2004, art. 30, inciso II e art. 40, inciso III;

3. TE - Tarifa de Energia: valor monetário unitário determinado pela ANEEL, em R\$/MWh, utilizado para efetuar 0 faturamento mensal pela distribuidora referente ao consumo de energia dos seguintes contratos:

a) Contrato de Compra de Energia Regulada CCER, nos termos da Resolução Normativa no 414/2010, art. 62;

b) Contrato de fornecimento de consumidores do grupo A, nos termos da Resolução Normativa no 414/2010, art. 63;

c) Contrato de Adesão de consumidores do grupo B, nos termos da Resolução Normativa no 414/2010, art. 60;

d) Contrato de Compra e Venda da Energia $\mathrm{CCE}$, para suprimento de concessionária ou permissionária de distribuição com mercado inferior a $500 \mathrm{GWh} / \mathrm{ano}$;

4. Bandeiras Tarifárias: sistema tarifário que tem como finalidade sinalizar aos consumidores faturados pela distribuidora, por meio de adicional na tarifa de energia, dos custos da geração de energia elétrica.

\subsubsection{SUBGRUPOS E MODALIDADES TARIFÁRIAS}

Para os usuários do sistema de distribuição, a TUSD diferencia-se por subgrupo, posto e modalidade tarifária. Já a TE se diferencia por posto e modalidade tarifária.

Os usuários do sistema de distribuição são classificados em grupos e subgrupos tarifários, conforme incisos XXXVII e XXXVIII, do art. 20, da Resolução Normativa n 414/2010.

Os postos tarifários são:

1. Posto Tarifário Ponta: período composto por três horas diárias consecutivas definidas pela distribuidora considerando a curva de carga de seu sistema elétrico, aprovado pela ANEEL para toda a área de concessão, exceto para fins de semana e os feriados definidos na Resolução Normativa no 414/2010, art. 20, inciso LVIII;

2. Posto Tarifário Intermediário: período de duas horas, sendo uma hora imediatamente 
anterior e outra imediatamente posterior ao posto ponta;

3. Posto Tarifário Fora de Ponta: período composto pelo conjunto das horas diárias consecutivas e complementares àquelas definidas nos postos ponta e intermediário.

As modalidades tarifárias são:

1. Modalidade tarifária horária Azul: aplicada às unidades consumidoras do grupo A, caracterizada por tarifas diferenciadas de consumo de energia elétrica e de demanda de potência, de acordo com as horas de utilização do dia;

2. Modalidade tarifária horária Verde: aplicada às unidades consumidoras do grupo A, caracterizada por tarifas diferenciadas de consumo de energia elétrica, de acordo com as horas de utilização do dia, assim como de uma única tarifa de demanda de potência;

3. Modalidade tarifária Convencional Binômia: aplicada às unidades consumidoras do grupo A, caracterizada por tarifas de consumo de energia elétrica e demanda de potência, independentemente das horas de utilização do dia;

4. Modalidade tarifária horária Branca: aplicada às unidades consumidoras do grupo B, conforme Resolução Normativa no 414/2010, caracterizada por tarifas diferenciadas de consumo de energia elétrica, de acordo com as horas de utilização do dia;

5. Modalidade tarifária Convencional Monômia: aplicada às unidades consumidoras do grupo $B$, caracterizada por tarifas de consumo de energia elétrica, independentemente das horas de utilização do dia;

6. Modalidade tarifária Geração: aplicada às centrais geradoras e aos agentes importadores conectados aos sistemas de distribuição, caracterizada por tarifas de demanda de potência, independentemente das horas de utilização do dia;

7. Modalidade tarifária Distribuição: aplicada às concessionárias ou às permissionárias de distribuição conectadas aos sistemas de outra distribuidora, caracterizada por tarifas diferenciadas de demanda de potência, de acordo com as horas de utilização do dia, e de consumo de energia elétrica;

8. Modalidade tarifária pré-pagamento: aplicada no faturamento das unidades consumidoras que aderirem ao sistema de faturamento pré-pago nos termos da Resolução Normativa no 610/2014;

\subsubsection{COMPOSIÇÃO DA TARIFA DE USO DO SISTEMA DE DISTRIBUIÇÃO - TUSD}

Os custos regulatórios que formam a TUSD são definidos no processo de reajuste ou revisão tarifária.

As funções de custos da TUSD são formadas de acordo com os seguintes componentes tarifários:

1. TUSD TRANSPORTE - parcela da TUSD que compreende a TUSD FIO A e a TUSD FIO B, sendo:

a) TUSD FIO A - formada por custos regulatórios pelo uso de ativos de propriedade de terceiros, compreendida por:

i. Uso dos sistemas de transmissão da Rede Básica;

ii. Uso dos transformadores de potência da Rede Básica com tensão inferior a 230 kV e das DIT compartilhadas;

iii. Uso dos sistemas de distribuição de outras distribuidoras; e

iv. Conexão às instalações de transmissão ou de distribuição.

b) TUSD FIO B - formada por custos regulatórios pelo uso de ativos de propriedade da própria distribuidora que compõem a Parcela B, compreendida por:

i. Custo anual dos ativos (CAA);

ii. Custo de administração, operação e manutenção (CAOM).

2. TUSD ENCARGOS - parcela da TUSD que recupera os custos de:

a) Pesquisa e Desenvolvimento e Eficiência Energética - P\&D_EE;

b) Taxa de Fiscalização de Serviços de Energia Elétrica - TFSEE;

c) Contribuição para o Operador Nacional do Sistema Elétrico - ONS;

d) Quota da Conta de Desenvolvimento Energético-CDE; e

e) Programa de Incentivo às Fontes Alternativas de Energia Elétrica PROINFA.

3. TUSD PERDAS - parcela da TUSD que recupera os custos regulatórios com:

a) Perdas técnicas do sistema da distribuidora;

b) Perdas não técnicas;

c) Perdas na Rede Básica devido às perdas regulatórias da distribuidora; e

d) Receitas Irrecuperáveis. 


\subsubsection{COMPOSIÇÃO DA TARIFA DE ENERGIA - TE}

Os custos regulatórios que formam a TE são definidos no processo de reajuste ou revisão tarifária. As funções de custos da TE são formadas de acordo com os seguintes componentes tarifários:

1. TE ENERGIA - é a parcela da TE que recupera os custos pela compra de energia elétrica para revenda ao consumidor, incluindo:

a) compra nos leilões do Ambiente de Contratação Regulada - ACR;

b) Quota de Itaipu;

c) Geração própria;

d) Aquisição do atual agente supridor;

e) Compra de geração distribuída.

2. TE ENCARGOS - é a parcela da TE que recupera os custos de:

a) Encargos de Serviços de Sistema - ESS e Encargo de Energia de Reserva - EER;

b) Pesquisa e Desenvolvimento e Eficiência Energética - P\&D_EE;

c) Contribuição sobre Uso de Recursos Hídricos - CFURH; e

d) Quota da Conta de Desenvolvimento Energético - $\mathrm{CDE}$, compreendida por:

i. Amortização da Conta no Ambiente de Contratação Regulada - CONTA -ACR;

ii. Devolução dos recursos da CDE de que trata o Decreto no 7.945, de 8 de março de 2013.

3. TE TRANSPORTE - é a parcela da TE que recupera os custos de transmissão relacionados ao transporte de Itaipu e à Rede Básica de Itaipu.

4. TE PERDAS - é a parcela da TE que recupera os custos com perdas na Rede Básica devido ao mercado de referência de energia.

\subsubsection{FATURA DO CONSUMIDOR FINAL}

A distribuidora deve disponibilizar aos consumidores do grupo $B$ e aos consumidores do grupo A optantes pelas tarifas do grupo B, o valor correspondente à energia, ao serviço de distribuição, à transmissão, às perdas de energia, aos encargos setoriais e aos tributos.

A informação mencionada no item anterior darse-á pela disponibilização da mesma no sítio da distribuidora, por meio de comunicado aos consumidores ou pela fatura de energia elétrica que corresponde ao custo faturamento dos componentes tarifários associados que estão representados na Tabela 3.
Tabela 3: Valores na fatura.

\begin{tabular}{|l|l|}
\hline Custos & Faturamentos dos componentes associados \\
\hline Energia & $\begin{array}{l}\text { Energia TE-ENERGIA, TE-TRANSPORTE e } \\
\text { bandeira tarifária em vigor. }\end{array}$ \\
\hline $\begin{array}{l}\text { Serviços de } \\
\text { Distribuição }\end{array}$ & TUSD - FIO B. \\
\hline Transmissão & TUSD - FIO A. \\
\hline $\begin{array}{l}\text { Perdas de } \\
\text { Energia }\end{array}$ & TUSD - PERDAS e TE -PERDAS. \\
\hline $\begin{array}{l}\text { Encargos } \\
\text { Setoriais }\end{array}$ & TUSD - ENCARGOS e TE - ENCARGOS. \\
\hline
\end{tabular}

Fonte: Módulo ANEEL [2].

Para os consumidores do grupo A, a ANEEL disponibilizará, em até 15 (quinze) dias após publicação da respectiva resolução homologatória, em seu sítio na internet, os valores das tarifas segregados nos componentes tarifários.

\section{PREÇO NO AMBIENTE DE CONTRATAÇÃO LIVRE}

As operações no mercado livre de energia brasileiro ocorrem baseadas na expectativa que os agentes têm quanto ao valor do Preço de Liquidação das Diferenças - PLD, que é o preço de curto prazo da eletricidade. O PLD apresenta alta volatilidade devido às suas características físicas singulares, tais como [4]:

1. Impossibilidade de seu armazenamento como produto, no sentido que não é possível comprar eletricidade hoje e estoca-la para venda futura;

2. A incerteza da demanda;

3. A inflexibilidade de preço da demanda;

4. A hidrologia;

5. O longo tempo de resposta (lead-time) necessário para a expansão da geração a fim de atender ao crescimento da demanda.

O preço de energia depende da disposição a vender do gerador - valor mínimo que um gerador aceitaria por um contrato, considerando seu custo de oportunidade (liquidar a sua geração no mercado "spot"). E disposição a comprar do consumidor valor máximo que um consumidor aceitaria por um contrato, considerando seu custo de oportunidade (retorno para o ACR ou contratos "spot" de curto prazo).

Em um sistema equilibrado, o preço resultante tende a ser próximo ao que o consumidor está disposto a contratar, embora o maior poder de negociação esteja com o gerador. 
Em um ambiente em que sobra energia, a situação se reverte e a disposição a vender dos geradores passa a determinar o preço. Os limites entre a disposição a comprar do consumidor e a disposição a vender dos geradores é a faixa de negociação.

O Balcão Brasileiro de Energia Elétrica - BBCE disponibiliza em seu sítio a curva Forward para preços futuros, a metodologia do cálculo é a média ponderada dos negócios realizados entre os que acessam a plataforma. Essa curva, que pode ser vista na Figura 3 e Figura 4 é um bom balizador para os negócios realizados no Mercado Livre.

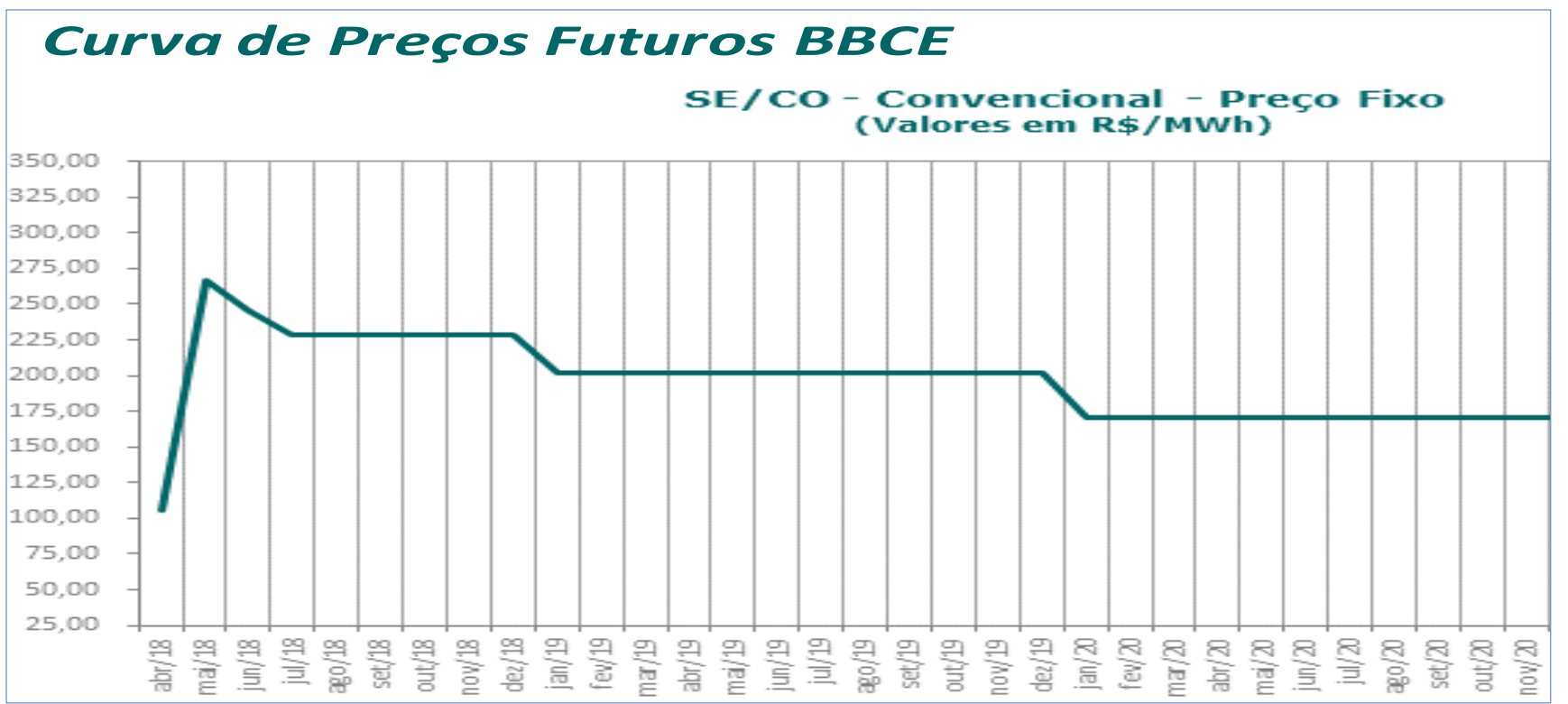

Figura 3: Curva Forward para preços futuros.

Fonte: BBCE.

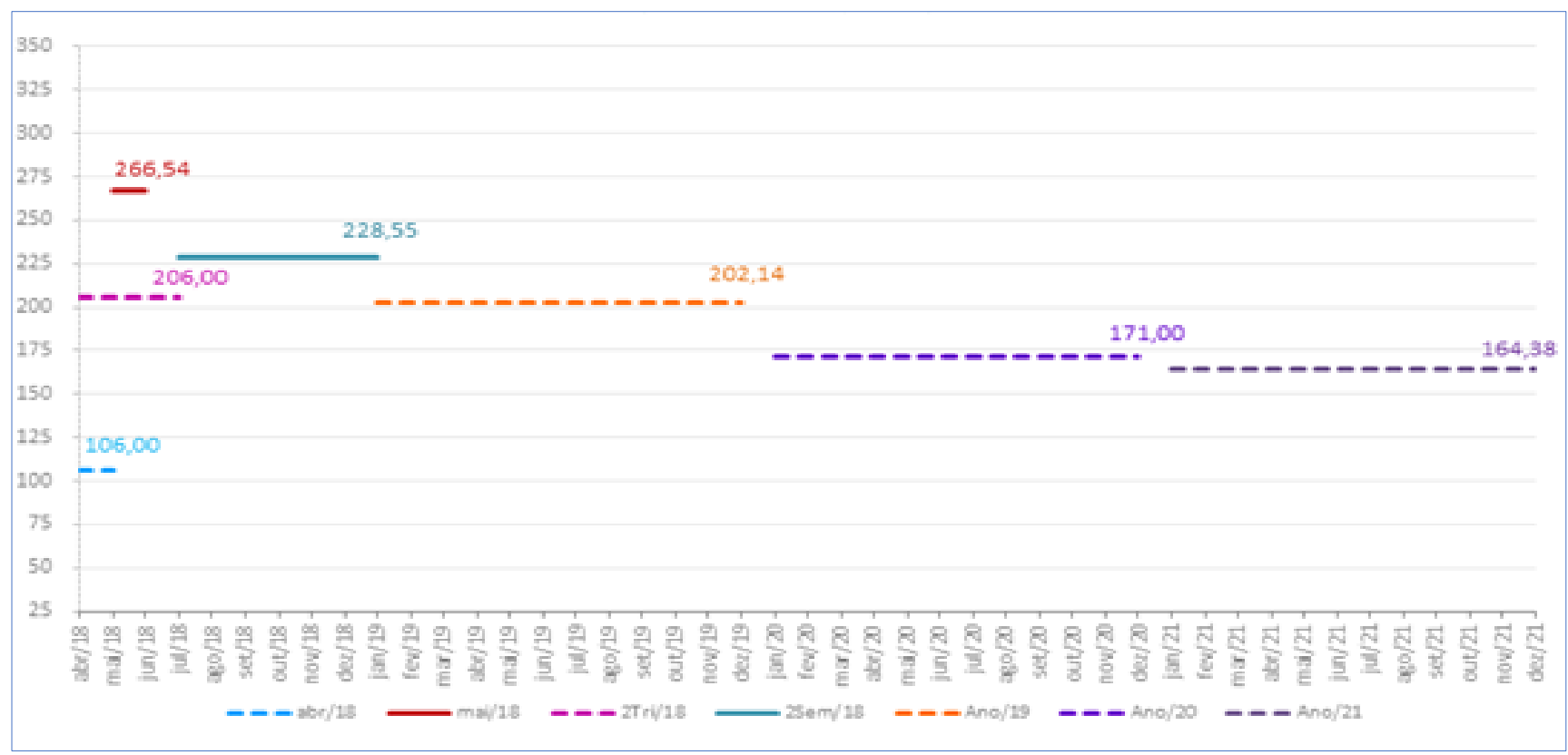

Figura 4: Curva Forward para preços futuros.

Fonte: BBCE. 


\section{ESTUDO DE VIABILIDADE MERCADO LIVRE VERSUS CATIVO}

A finalidade de migrar entre os ambientes de comercialização é puramente econômica, compara-se o somatório dos custos que envolvem energia elétrica em ambos os mercados e se escolhe o mais vantajoso.

É necessário verificar, primeiramente, se o consumidor é apto a migrar e qual tipo de energia Ihe garante maior economia.

\subsection{Estudo Comparativo}

O estudo de viabilidade permite que a empresa interessada em gerir os contratos de energia dos clientes possa analisar cada caso individualmente, procurando estabelecer as melhores condições contratuais para o perfil do cliente em questão. Em vista disso, os cálculos foram elaborados para um consumidor de médio porte, pode-se observar na Figura 5 uma simulação de sua fatura no ambiente regulado.
A TUSD é o pagamento à distribuidora pela utilização das suas instalações de distribuição de energia, é a cobrança de que a distribuidora tira sua receita principal. Já a TE cobrada pelo mercado cativo, é apenas soma dos custos com a aquisição da energia em leilões regulados, praticamente um repasse dos valores. Para o ambiente livre, são as projeções de carga e geração do mercado que definem o seu preço. $O$ consumidor possui um tempo mínimo para avisar a concessionária sobre a migração, que é estabelecido no contrato de fornecimento de energia com a concessionária, ou seja, o cliente deverá informar a distribuidora sobre sua migração ao Mercado Livre com 180 dias de antecedência. A ANEEL define que quando ocorre a migração para o Mercado Livre de energia o consumidor só poderá retornar ao Mercado Cativo após 5 anos da migração ou no caso de a concessionária de sua região aceitar o seu retorno.

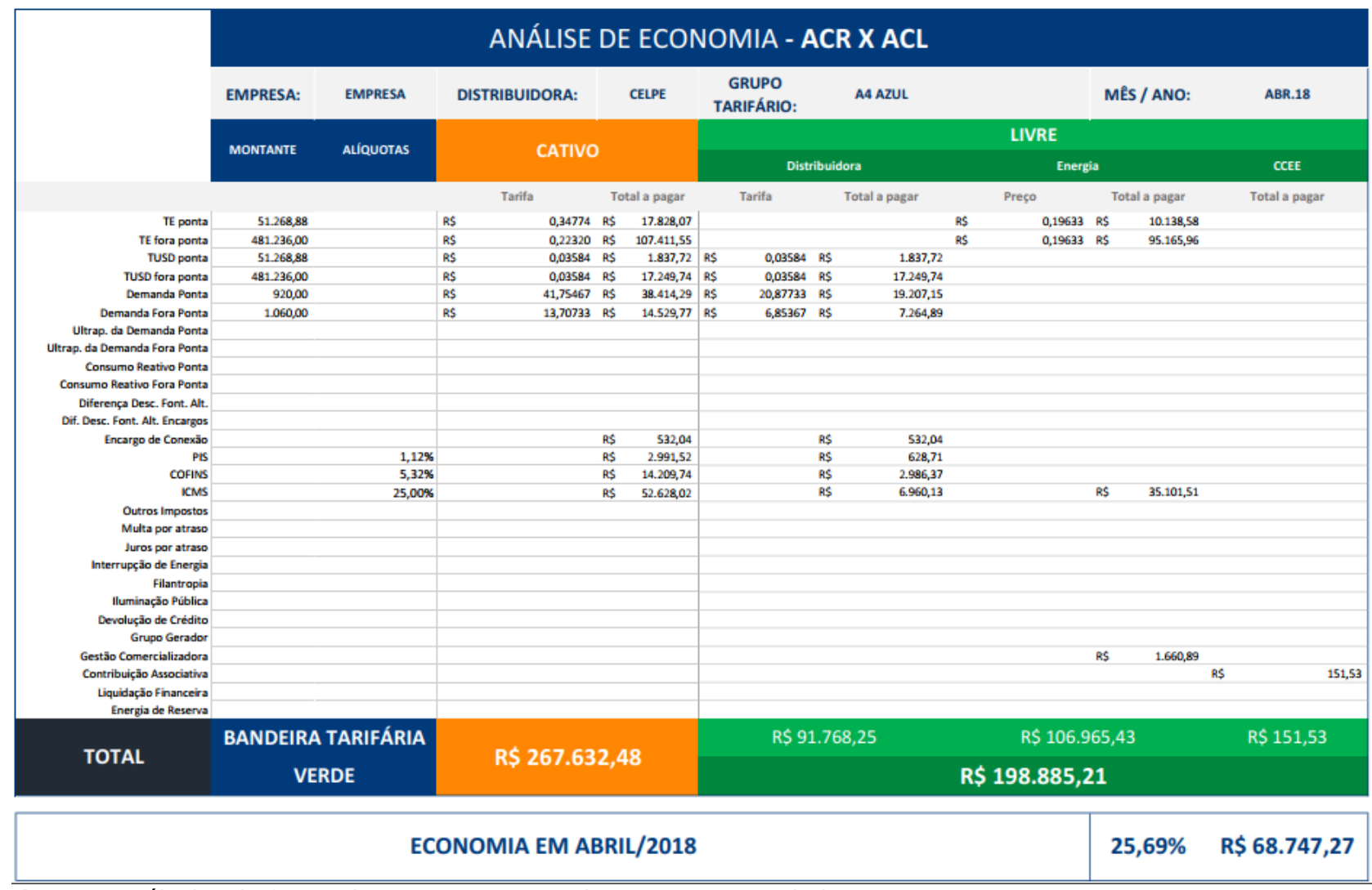

Figura 5: Cálculos de fatura de energia no Mercado Cativovs Mercado livre.

Fonte: Os Autores. 
Ao interpretar a Figura 5, tem-se que as tarifas de consumo para o Mercado Cativo, correspondente à Tarifa de Energia- TE que é cobrada pela distribuidora, custaram $\mathrm{R} \$ 125.239,62$. As tarifas de demanda, que também são tarifas de TUSD, elas, independentemente se o consumidor está no ambiente regulado ou livre, são cobradas pela distribuidora, tiveram um custo de $\mathrm{R} \$ 52.944,07$ no ambiente regulado. Sabe-se que a conta de energia nesse mercado é composta da TUSD, TE, encargos e impostos, resultando no valor de $\mathrm{R} \$ 267.632,48$.

Já no Mercado Livre, para o mesmo consumidor, os cálculos mostram relevante redução nos custos da sua conta de energia, como mostrado ainda na Figura 5. Nela é possível observar que é dado um desconto em uma parcela da TUSD, pois o consumidor de médio porte consome energia incentivada especial. Além disso, os valores de consumo, para o mesmo montante do $A C R$, são também inferiores, tanto para o posto ponta como para o fora ponta. É nesse parâmetro que se encontra o principal fundamento para a migração, haja vista que ele é o elemento mais oneroso da conta e que pode ser negociado livremente entre as partes, de forma que cheguem num consenso que agrade ambos. Desse modo, ao somar as custas de consumo, TUSD, encargos e impostos, o preço total no ambiente livre é $R \$ 198.885,21$.

Ou seja, comparando-se os dois casos, é possível perceber que o valor total da conta no $A C L$ é $25,69 \%$ abaixo do valor no $A C R$, o que gera uma economia $\mathrm{R} \$ 68.747,27$ caso o consumidor opte por migrar para o ambiente livre.

\section{CONCLUSÕES}

Analisando a legislação acerca dos ambientes de contratação de energia, pode-se observar que ambos possuem regulamentação bem definida e 0 consumidor precisa analisar se em seu enquadramento qual dos modelos apresenta maior economia. Considerando o curto, o médio e o longo prazo.

O caso, objeto de estudo, mostrou também que o ambiente livre é bastante viável quando se busca melhores condições de preço, já que ele apresenta uma economia financeira considerável em relação à contração em mercado distinto. A despeito desse benefício, foi possível conhecer algumas desvantagens relativas ao $A C L$, como: o recebimento de contas separadas para tarifas de consumo e distribuição, vulnerabilidade de empresas exclusivamente privadas, entre outros supracitados.

Por fim, caso o interesse do cliente seja uma contração com mais flexibilidade e com um preço abaixo do convencional, o ACL é uma ótima opção, principalmente para os grandes consumidores de energia elétrica, já que o desconto é obtido sobre a quantidade consumida.

\section{REFERÊNCIAS}

[1] EPE. Resenha Mensal do Mercado de Energia Elétrica. Brasil, mar. 2018.

[2] ANEEL. Módulo 7: Estrutura Tarifária das Concessionárias de Distribuição. Brasil, 15 de abril de 2015.

[3] ASSOCIAÇÃO BRASILEIRA DOS COMERCIALIZADORES DE ENERGIA. Cartilha mercado livre de energia elétrica: um guia básico para consumidores potencialmente livres e especiais. [S.I.]: ABRACEEL, 2 ABR. 2018. Disponível em: http://worldse.com.br/mercadolivre-de-energia-eletrica-um-guia-basico-paraconsumidores-potencialmente-livres-eespeciais/.

[4] PARENTE, G. V. U. Novo modelo do setor elétrico brasileiro mercado livre de energia. Campina Grande: UFCG, 2016. 